\title{
MOLECULAR WEIGHT DETERMINATION FOR 1,2,1,2-POLYPROPADIENE
}

\author{
J. G. van Ommen, H. A. Polman, P. C. J. M. van Berkel and \\ P. J. Gellings \\ Twente University of Technology, Department of Chemical Technology, P.O. Box 217, \\ 7500 AE Enschede, The Netherlands
}

(Receited 8 February 1980)

\begin{abstract}
By using standard bromination conditions, the insoluble 1,2,1,2-polypropadiene (formed by $\mathrm{Ni}(\mathrm{acac})_{2}$ or $\mathrm{Co}(\mathrm{acac})_{2}$ or ${ }_{3}, \mathrm{C}_{3} \mathrm{H}_{4},(i \mathrm{Bu})_{3} \mathrm{Al}$ catalysts) is transformed into a soluble bromopolypropadiene. Using this technique, determination of molecular weight becomes possible. It was found that the molecular weight increases with polymerization time until a steady value is reached. As the polymer yield continues to increase when a constant molecular weight has been reached, chain transfer must occur. The molecular weight of polybromopropadiene was independent of the concentrations of the catalyst components. From experiments with crosslinked polymers and from theoretical considerations, it was deduced that the low solubility of the original 1,2,1,2-polypropadiene is due to its high crystallinity.
\end{abstract}

\section{INTRODUCTION}

Polypropadiene of highly regular structure can be prepared by Ziegler-catalysts [1,2] or Rh (I) complexes [3]. This polymer is only slightly soluble in solvents such as boiling toluene, chlorobenzene or xylene [1].

Baker [4] and Havinga [5] also obtained only slightly soluble polymers. Otsuka [6] verified this Ziegler-type polymerization with $\mathrm{Ni}(\mathrm{acac})_{2} \mathrm{Et}_{3} \mathrm{Al}$ and claimed that he obtained an insoluble gel. With $\pi$-allylnickel complexes no gel was formed, and this was proposed as the explanation of the good solubility of this polymer. Tadokoro [7] found that the Ziegler-type polymer was more regular than the $\pi$-allyl type. van Ommen et al. $[8,9]$ showed that bis- $\pi$-allyl-nickel gives a polymer, with the same i.r.spectrum as polymers formed with catalysts based on $\mathrm{Ni}(\mathrm{acac})_{2}$ [8] or $\mathrm{Co}(\mathrm{acac})_{2}$ [9], provided the monomer is added to the catalyst before the aluminium alkyl. They also showed $[8,10]$ that the same polymers as synthesized by Otsuka [6] could be obtained by adding pyridine [8] to the Ziegler-catalysts or by using $\pi$-allylnickel chloride [10]. The polymer thus obtained contains the<smiles>[Y1]CC(=C)CC(=C)I</smiles>

and the conjugated 1,2,2,1-structural elements<smiles>C=C(CI)C(=C)CI</smiles>

as shown by i.r.-spectra $[7,8]$. This irregularity of the polymer chain could be the cause of the good solubility of Otsuka's polymer $[6,11]$. Therefore it is not yet clear whether gel formation resulting from crosslinking or high crystallinity is the cause of the low solubility of highly regular 1,2,1,2-polypropadiene. This is one reason why a good method to determine the molecular weight of the 1,2,1,2-polypropadiene was sought. The other reason is that the result could give insight into the mechanism of the polymerization, by measuring the molecular weight as a function of polymerization time, and of the $\mathrm{Al}$-and $\mathrm{Ni}$-concentrations.

\section{MOLECULAR WEIGHT DETERMINATION}

For determination of the molecular weight of a polymer, solubility is a primary condition. As stated already, there is no good solvent for crystalline 1,2,1,2-polypropadiene prepared by Ziegler-catalysts. One of the reasons could be the easy cross-linking of the polymer by oxygen as noticed already by Havinga [5]. In the kinetic experiments [10], it was observed that, even in a $\mathrm{N}_{2}$ atmosphere, it was not possible to dissolve an appreciable amount of polymer at room temperature, once it had precipitated.

By addition to the double bonds in the polymer, an attempt was made to improve the solubility and the stability to crosslinking by $\mathrm{O}_{2}$. Hydrogenation did not give reproducible results. $\mathrm{HCl}$ added only to part of the double bonds and left the polymer still difficult to dissolve. By using $\mathrm{Cl}_{2}$, not only the unsaturated double bonds disappeared but also the molecular weight decreased dramatically with chlorination time. It was found in the literature [14] that, in the bromination of butyl-rubber, the breakdown was relatively small compared with that during chlorination. Although butylrubber has only $3-5 \%$ unsaturated groups and is therefore not the best comparison for 1,2,1,2-polpropadiene, it was decided to investigate the possibility of using bromination in order to obtain a more readily soluble and stable polymer.

\section{EXPERIMENTAI}

\section{Preparation of polybromopropadiene}

The polymerization was performed as described earlier [1]. If toluene was used as solvent it was evaporated com- 
Table 1. Molecular weights of bromopolypropadiene as a function of bromination time and catalyst composition. Polymerization time $24 \mathrm{hr}$

\begin{tabular}{|c|c|c|c|c|c|c|}
\hline $\begin{array}{c}\mathrm{C}_{\mathrm{Ni} \text { or Co(acac })_{2}} \\
\left(\mathrm{~mol} \mathrm{1}^{-1}\right)\end{array}$ & $\mathrm{Al} / \mathrm{Ni}(\mathrm{Co})$ & $\begin{array}{c}\text { Bromination } \\
\text { time } \\
\text { (hr) }\end{array}$ & $\begin{array}{c}\text { Osmometry } \\
\left(\overline{\mathrm{M}}_{\mathrm{n}} \times 10^{-3}\right)\end{array}$ & $\overline{\mathrm{M}}_{\mathrm{n}} \times 10^{-3}$ & $\begin{array}{l}\text { GPC } \\
\overline{\mathbf{M}}_{w} \times 10^{-3}\end{array}$ & $\overline{\mathrm{M}}_{\mathrm{w}} / \overline{\mathrm{M}}_{\mathrm{n}}$ \\
\hline $22 \cdot 10^{-4}$ & 100 & 5 & 16 & 16 & 32 & 2 \\
\hline $44 \cdot 10^{-4 *}$ & 36 & 20 & 17 & 18 & 27 & 1.5 \\
\hline $44 \cdot 10^{-4 *}$ & 36 & 20 & 19 & 19 & 27 & 1.4 \\
\hline $44 \cdot 10^{-4 *}$ & 36 & 20 & 18 & 19 & 27 & 1.4 \\
\hline $40 \cdot 10^{-3}$ & 5.5 & 1 & & 15 & 32 & 2.1 \\
\hline $40 \cdot 10^{-3}$ & 5.5 & 2 & & 14 & 25 & 1.8 \\
\hline $40 \cdot 10^{-3}$ & 5.5 & 5 & & 14 & 24 & 1.7 \\
\hline $40 \cdot 10^{-3}$ & 5.5 & 22 & & 11 & 19 & 1.7 \\
\hline $40 \cdot 10^{-3}$ & 5.5 & 48 & & 11 & 19 & 1.7 \\
\hline $40 \cdot 10^{-3}$ & 2 & 20 & & 16 & 28 & 1.8 \\
\hline $40 \cdot 10^{-3}$ & 3.4 & 20 & & 14 & 23 & 1.6 \\
\hline $40 \cdot 10^{-3}$ & 9 & 8 & & 13 & 23 & 1.8 \\
\hline $40 \cdot 10^{-3}$ & 9 & 24 & & 12 & 20 & 1.7 \\
\hline $40 \cdot 10^{-3}$ & 9 & 20 & & 12 & 21 & 1.8 \\
\hline $44 \cdot 10^{-4 *}$ & 36 & 20 & & $27 \dagger$ & $52 \dagger$ & 1.9 \\
\hline
\end{tabular}

* $\mathrm{Co}(\mathrm{acac})_{2}$

+ Bromination in air, $\bar{M}_{n}$ and $\bar{M}_{w}$ are determined for the soluble part

pletely and then $10-15 \mathrm{ml}$ dried, $\mathrm{O}_{2}$ free, benzene were added to about $0.5 \mathrm{~g}$ of the polymer; the reaction vessel was then cooled to $6^{\circ} .5-6 \mathrm{ml}$ of pure $\mathrm{Br}_{2}$ were then added dropwise. The polymer was stirred with the $\mathrm{Br}_{2}$ for $8 \mathrm{hr}$ at $0^{\circ}$ and filtered to remove the catalyst. Up to this point, it was essential to work under an $\mathrm{O}_{2}$-free atmosphere otherwise there was crosslinking. The solution of polybromopropadiene in benzene thus obtained was added to $50 \mathrm{ml}$ of diethylether. The polymer precipitated and was filtered and washed with about $500 \mathrm{ml}$ diethylether until the washings were colourless. The polymer was then dried at room temperature and $0.1 \mathrm{~mm} \mathrm{Hg}$.

\section{Molecular weight determination}

Gell permeation chromatography (GPC) determinations of $\bar{M}_{n}$ and $\bar{M}_{w}$ were performed on a Waters 4-column instrument. The column length was $4 \mathrm{ft}$. per column, o.d. $3 / 8 \mathrm{in}$. and the porosity sequence of the cross-linked polystyrene packing (Stryra gel) $10^{5}-3.10^{4}-10^{3}-250 \AA$. The eluant was tetrahydrofuran (Baker p.a.) (a good solvent for polybromopropadiene), the flow rate $1 \mathrm{ml} \mathrm{min}^{-1}$, the temperature $30^{\circ}$ and the syphon volume $5.58 \mathrm{ml}$. Polymer solutions $(0.25 \%)$ were injected in $40 \mathrm{sec}$ and detected with a refractivity increment.

The relation between elution volume and $\bar{M}_{n}$ was established by determination of $\overline{\mathbf{M}}_{n}$ for several samples by means of a Hallikainen automatic membrane-osmometer. The membrane was Sartorius SM 11539 (ultracella "allerfeinst"). Five polymer solutions of concentrations between 0.1 and $0.5 \%$ in toluene (Merck p.a.) were examined at $25^{\circ}$. An empirical correction for peak-broadening (determined for a series of standard polystyrenes) was applied: $\quad\left(\overline{\mathrm{M}}_{n}\right) \mathrm{GPC}=1.20 \times\left(\overline{\mathrm{M}}_{\mathrm{n}}\right)$ true, $\quad\left(\overline{\mathrm{M}}_{\mathrm{w}}\right) \mathrm{GPC}=$ $1.00 \times\left(\overline{\mathrm{M}}_{\mathrm{w}}\right)$ true.

Elemental analyses were performed by the Organic Chemical Institute TNO, Utrecht, The Netherlands.

\section{RESULTS}

Bromination of the 1,2,1,2-polypropadiene produced a soluble polymer and, according to the i.r.spectrum, almost all double bonds disappeared (1635-890 $\mathrm{cm}^{-1}$ [7]) while the $-\mathrm{CH}_{2}-$ groups remained unchanged $\left(1420 \mathrm{~cm}^{-1}[7]\right)$.

The NMR spectra show, in agreement with the i.r. spectra, that the broad absorption of the $=\mathrm{CH}_{2}$ group at $\delta=5$ ppm disappears after a short bromination time, while at $\delta=4.5 \mathrm{ppm}$ a new broad absorption appears, attributed to the $-\mathrm{CH}_{2} \mathrm{Br}$ group. The broad absorption of the $-\mathrm{CH}_{2}-$ group in the polymer chain at $\delta=2.5$ remains unchanged during the bromination.

There was only a small tendency for decrease in molecular weight during bromination, see Table 1 . This result is only obtained under mild conditions, viz. $6^{\circ}$ and low $\mathrm{Br}_{2}$ concentration. If the temperature is increased to $25^{\circ}$ and $\mathrm{Br}_{2}$ is not diluted by benzene, a large decrease of molecular weight is observed $\left(\bar{M}_{n}=1600\right)$. This last observation casts some doubt on the relation between the molecular weight of bromopolypropadiene and that of the original polypropadiene. However, the reproducibility of the results (see Table 1) suggests that the molecular weights of the bromopolypropadiene are indeed representative for those of the original polymer.

The elemental analysis of the bromopolypropadiene is not in agreement with the expected theoretical values (Table 2). However, after $2 \mathrm{hr}$, the molecular weight of one unit is constant (165) within $\pm 3 \%$. This can be explained by assuming that part of the added bromine is eliminated again as $\mathrm{HBr}$. The formation of this compound during bromination was actually observed, also in accordance with the results of the bromination of butylrubber [14].

Renewed addition of a second molecule $\mathrm{Br}_{2}$ followed by a second elimination of $\mathrm{HBr}$ is also possible. In agreement with this, it was found that prolonged bromination led to a new absorption in the i.r.-spectrum, attributed to this brominated double bond $\left(1670 \mathrm{~cm}^{-1}\right)$. In agreement the NMR spectra showed broad absorptions at $\delta=7 \mathrm{ppm}$ and $\delta=7.5 \mathrm{ppm}$ which could be attributed to the $-\mathrm{CHBr}_{2}$ and the $=\mathrm{CHBr}$ group repectively.

If bromination is not performed in an inert atmosphere, the molecular weight increased and the i.r.spectrum of the product showed a $=\mathrm{C}=\mathrm{O}$ absorption at $1700 \mathrm{~cm}^{-1}$ and a $\mathrm{C}-\mathrm{O}-\mathrm{C}$ absorption at 
Table 2. Elemental analysis of bromopolypropadiene

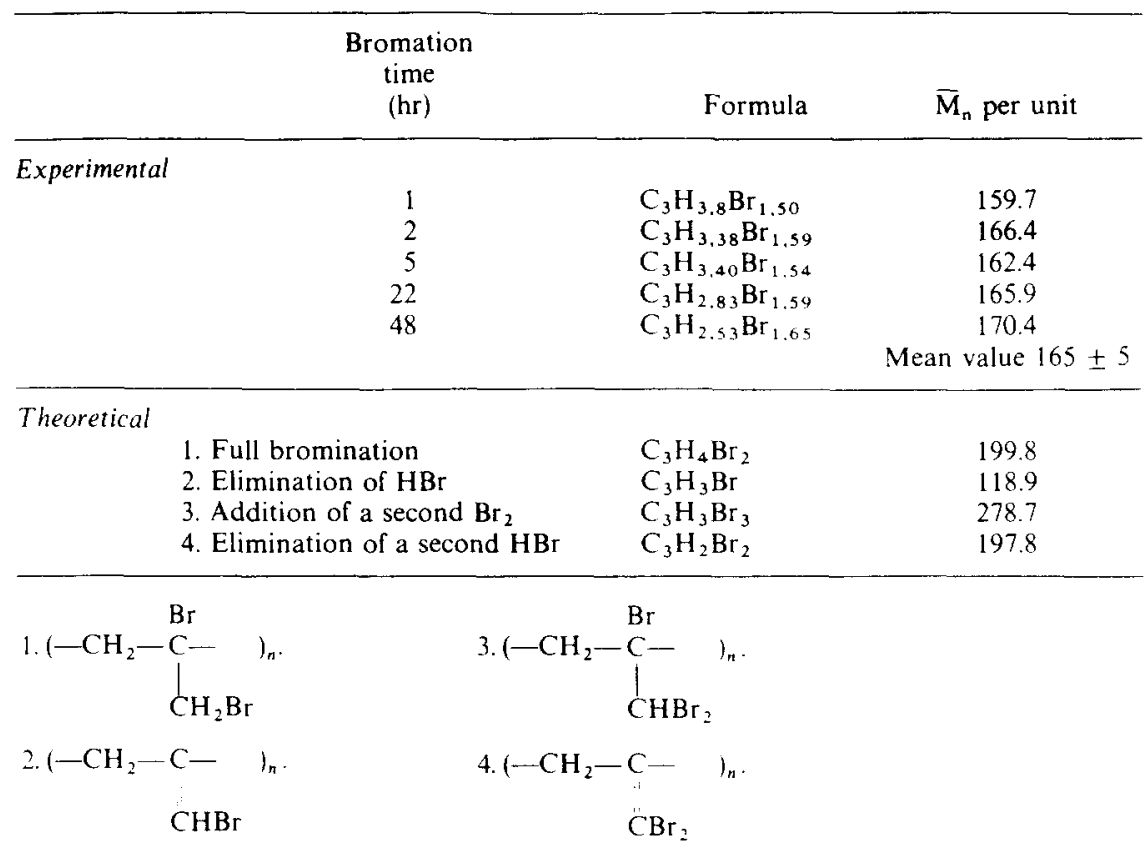

$1110 \mathrm{~cm}^{-1}$, indicating that part of the polypropadiene is oxidized and crosslinked and the polymer thus obtained is only partly soluble. Table 1 also shows that the $\mathrm{Al} / \mathrm{Ni}$ ratio has little influence on $\overline{\mathrm{M}}_{\mathrm{n}}$ if polymerization proceeds for $24 \mathrm{hr}$. Table 3 shows that, especially at the beginning, the molecular weight of the polymer and the spread $\left(\overline{\mathrm{M}}_{w} / \overline{\mathrm{M}}_{n}\right)$ increase with polymerization time.

\section{DISCUSSION}

From the results obtained with high $\mathrm{Br}_{2}$ concentrations, it follows that chain breakdown can occur. The relatively low molecular weight of about 16,000 , corresponding to a chain length of about 100 monomer units and obtained under mild bromination conditions, is therefore somewhat uncertain. The fact remains, however, that unlike the case with $\mathrm{Cl}_{2}$, the results are reproducible. From theoretical considerations [15] it follows that highly crystalline isotactic polystyrene with a chainlength of only 20 monomer units is almost insoluble, if the mixture of the solvent with the molten polymer is ideal, i.e. no heat or volume changes occur. It is also known that 1,2-poly-

Table 3. Influence of polymerization time on the molecular weight of 1,2,1,2-propadiene obtained by a $\mathrm{Ni}(\mathrm{acac})_{2}$ $\left(6 \cdot 10^{-3} \mathrm{~mol} 1^{-1}\right) \mathrm{Al} / \mathrm{Ni}=50$ catalyst at $25^{\circ}$ in toluene

\begin{tabular}{cccc}
$\begin{array}{c}\text { Polymerization time } \\
(\text { min) }\end{array}$ & $\overline{\mathrm{M}}_{\mathrm{n}} \times 10^{-3}$ & $\overline{\mathbf{M}}_{\mathbf{w}} \times 10^{-3}$ & $\overline{\mathbf{M}}_{\mathrm{w}} / \overline{\mathbf{M}}_{\mathrm{n}}$ \\
\hline 6 & 3 & 4 & 1.3 \\
15 & 7.4 & $10-12$ & 1.6 \\
22.5 & - & 12 & - \\
30 & 8.6 & 15 & 1.7 \\
60 & 9.0 & 16 & 1.8 \\
$24 \mathrm{hr}$ & 13 & 23 & 1.8 \\
\hline
\end{tabular}

butadiene, with a structure similar to that of 1,2,1,2-polypropadiene, neither of which are elastomers, is also highly crystalline and almost insoluble and there is no indication that its insolubility is due to crosslinking $[16]$.

The observation that cross-linking occurs if the bromination is carried out in contact with air, resulting in a much higher molecular weight for the soluble part of the polymer, gives a strong indication that $\mathrm{Br}$, is not capable of breaking down a cross-linked polymer.

It was also observed that, during polymerization in the absence of $\mathrm{O}_{2}$, the polymer precipitated slowly from the solution. Once precipitated, however it could not easily be redissolved although bromination of this polymer produces a soluble product.

These results strongly suggest that the low solubility of the 1,2,1,2-polypropadiene results from high crystallinity [7]. This high crystallinity is also deduced from X-ray powder diffraction (see Fig. 1) The increase in solubility in various solvents upon addition of $\mathrm{Br}_{2}$ to the double bonds can be explained on the one hand by the loss of stereoregularity and the bulkiness of the $\mathrm{Br}$ atoms and on the other hand by the increased polarity causing a larger solvation energy. The brominated polymers are stable on exposure to air: even after 80 days $\bar{M}_{n}$ and $\bar{M}_{w}$ have not changed.

The reproducible results of the molecular weight determinations for polybromopropadiene indicate that these values are representative for the original 1,2,1,2-polypropadiene. In that case, Table 3 shows that the molecular weight of 1,2,1,2-polypropadiene increases with polymerization time.

If it is supposed that all $\mathrm{Ni}$ atoms are active in the polymerization and that these continue chain growth until an average length of about 100 units is obtained, we are able to calculate, using a value of $4.2 \mathrm{~min}^{-1}$ for $k_{p}$ as obtained from previous kinetic measurements 


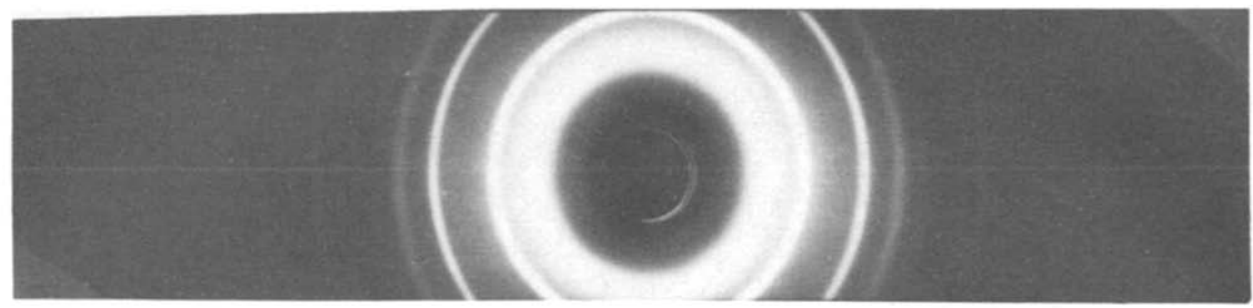

Fig. 1. X-ray powder diffraction pattern of 1,2,1.2-polypropadiene.

( $k_{2}$ in Ref. [10]), the molecular weight to be expected after a certain time.

$\begin{array}{ccc}\text { Time } & \overline{\mathbf{M}}_{\mathrm{n}} \text { observed } & \overline{\mathrm{M}}_{\mathrm{n}} \text { calculated } \\ 6 & 3000 & 4000 \\ 15 & 7400 & 10,000 \\ 30 & 8600 & 22,000 \\ 60 & 9000 & 41,000\end{array}$

For the first $15 \mathrm{~min}$, there is reasonable agreement between the observed and calculated values of $\overline{\mathbf{M}}_{n}$; the agreement might even improve if it is noted that deactivation lowers the polymerization rate constant to a final value of $0.84 \mathrm{~min}^{-1}$ [10]. This suggests that all $\mathrm{Ni}$ atoms are active centres for chain growth, with the same rate constant, at the start of the polymerization. If the polymerization is stopped at short times ( $<15 \mathrm{~min}$ ) we must find a low $\bar{M}_{n}$ and a narrow $\overline{\mathrm{M}}_{\mathrm{w}} / \overline{\mathrm{M}}_{\mathrm{n}}$ in agreement $\overline{\mathrm{M}}_{\mathrm{w}} / \overline{\mathrm{M}}_{\mathrm{n}}=1.3$ at $t=6 \mathrm{~min}$. The molecular weight becomes nearly constant for long polymerization times (Table 3 ). while polymer yield still increases. This suggests that termination of the chain growth occurs, possibly by crystallization of the polymer, after a certain length (100 monomer units) has been reached. Because termination does not take place at exactly the same chain length, $\overline{\mathrm{M}}_{\mathrm{w}} / \overline{\mathrm{M}}_{\mathrm{n}}$ must increase a little with time (Table 3 ).

This termination may occur in different ways if the catalyst is considered. One possibility is that only part of the $\mathrm{Ni}$ complexes formed after chain termination are active and able to start growth of a new chain while the rest remains inactive. The inactive part is not encapsulated in the polymer, as shown by $\mathrm{Ni}$ determinations in polymer and solvent [10]. This would lead to an apparent decrease of $k_{p}$ with time and a relatively small increase in $\overline{\mathrm{M}}_{w} / \overline{\mathrm{M}}_{\mathrm{n}}$. In this case, the decreasing rate constant $[10]$ shows that a decreasing amount of $\mathrm{Ni}$ complexes is active in the polymerization. A second possibility is that, as proposed originally $[10]$, the $\mathrm{C}_{2}$-bimetallic $\mathrm{Ni}-\mathrm{Al}$ catalystcomplexes are converted into less active complexes called $\mathrm{C}_{3}$ after termination of the chain growth. These $\mathrm{C}_{3}$-complexes must then produce 1,2,1,2-polymer chains at a lower rate but with approximately the same molecular weights as the $C_{2}$-complexes because $\overline{\mathrm{M}}_{\mathrm{n}}$ becomes nearly constant.

It is observed that, after prolonged polymerization $(24 \mathrm{hr})$, the polymer yield is still increasing, which would not be expected if every $\mathrm{Ni}$-atom could produce only one polymer chain. The yield of polymer, however, depends on $\mathrm{C}_{\mathrm{Ni}}$ and on the ratio $\mathrm{Al} / \mathrm{Ni}$ $[1,10]$ which can also be explained by both mechanisms proposed above.

\section{CONCLUSIONS}

(i) With standardized bromination conditions, it is possible to obtain information about the dependence of the molecular weight of 1,2,1,2-polypropadiene on polymerization time and on catalyst composition.

(ii) The molecular weight increases with polymerization time up to a constant final value.

(iii) As the polymer yield increases with time while the molecular weight becomes constant, chain transfer must take place.

(iv) The molecular weight is independent of the $\mathrm{Al}$ and $\mathrm{Ni}$ concentrations and also the use of $\mathrm{Co}$ instead of $\mathrm{Ni}$ has only a small influence.

(v) The insolubility of 1,2,1,2-polypropadiene in the absence of $\mathrm{O}_{2}$ is probably caused by the high crystallinity of this polymer and not by cross-linking.

Acknowledgements - We thank J. W. A. van den Berg and P. Mars for valuable discussions and G. van de Ridder for the measurements of molecular weights.

\section{REFERENCES}

1. J. E. van den Enk and H. J. van der Ploeg. J. Polym Sci., Al, 9, 2395 (1971).

2. J. E. van den Enk and H. J. van der Ploeg. J. Polym. Sci., Al, 9, 2403 (197I).

3. A. Giarusso, P. Gronchi, G. Ingrosso and L. Porri, Makromolek. Chem. 178, 1375 (1977).

4. W. P. Baker Jr, J. Polym. Sci., A 1. 655 (1963)

5. R. Havinga and A. Schors, J. Makromolek. Sci.. Part A 2. 1, 21 (1968).

6. S. Otsuka, J. am. chem. Soc. 87, 3017 (1965).

7. H. Tadokoro, M. Kobayashi, K. Mori, Y. Takahashi and S. Taniyama, J. Polym. Sci. Part C 22. 1031 (1969).

8. J. G. van Ommen, H. J. van der Ploeg, P. C. J. M. van Berkel and P. Mars, J. mol. Cataly's. 2, 409 (1977).

9. J. G. van Ommen, H. Stijntjes and P. Mars. J. mol. Catalys. 5, 1 (1979).

10. J. G. van Ommen, P. C. J. M. van Berkel and P. J. Gellings, Eur. Polym. J. 16, 745 (1980).

11. S. Otsuka, K. Mori, T. Suminoe and F. Imaizumi, Eur. Polym. J. 3, 73 (1967).

12. J. M. Evans, Polym. Engng Sci. 13, 401 (1973).

13. D. W. Koetsier, A. Bantjes and J. Feyen, J. Polym. Sci., Polym. Chem. Ed. 16, 511 (1978).

14. H. S. Makowski, in High Polymers (Edited by J. P. Kennedy and G. E. M. Törnqvist). Vol. 23, Part 2, p. 921. Interscience, New York (1969).

15. H. Morawetz, in High Polymers, Vol. 21, p. 75. Interscience, New York (1965).

16. H. Morawetz, in High Polymers, Vol. 21, p. 627. Interscience, New York (1965). 